\title{
Long noncoding RNAs in neuronal-glial fate specification and oligodendrocyte lineage maturation
}

Tim R Mercer ${ }^{1 \dagger}$, Irfan A Qureshi ${ }^{2,3,6 \dagger}$, Solen Gokhan ${ }^{2,3,6}$, Marcel E Dinger ${ }^{1}$, Guangyu Li ${ }^{3,6}$, John S Mattick ${ }^{{ }^{*}}$, Mark F Mehler $2,3,4,5,6^{*}$

\begin{abstract}
Background: Long non-protein-coding RNAs (ncRNAs) are emerging as important regulators of cellular differentiation and are widely expressed in the brain.

Results: Here we show that many long ncRNAs exhibit dynamic expression patterns during neuronal and oligodendrocyte (OL) lineage specification, neuronal-glial fate transitions, and progressive stages of OL lineage elaboration including myelination. Consideration of the genomic context of these dynamically regulated ncRNAs showed they were part of complex transcriptional loci that encompass key neural developmental protein-coding genes, with which they exhibit concordant expression profiles as indicated by both microarray and in situ hybridization analyses. These included ncRNAs associated with differentiation-specific nuclear subdomains such as Gomafu and Neat1, and ncRNAs associated with developmental enhancers and genes encoding important transcription factors and homeotic proteins. We also observed changes in ncRNA expression profiles in response to treatment with trichostatin $\mathrm{A}$, a histone deacetylase inhibitor that prevents the progression of OL progenitors into post-mitotic OLs by altering lineage-specific gene expression programs.
\end{abstract}

Conclusion: This is the first report of long ncRNA expression in neuronal and glial cell differentiation and of the modulation of ncRNA expression by modification of chromatin architecture. These observations explicitly link ncRNA dynamics to neural stem cell fate decisions, specification and epigenetic reprogramming and may have important implications for understanding and treating neuropsychiatric diseases.

\section{Background}

It has recently become evident that the majority of the mammalian genome is transcribed in a developmentally regulated manner producing tens of thousands of interleaved short and long ncRNAs [1-4]. Long ncRNAs, defined as greater than $200 \mathrm{nt}$ in length [5], exhibit specific temporal and spatial expression patterns in mouse brain [6], embryonic stem cell differentiation [7] and Tcell differentiation [8]. NcRNAs are also implicated in neural developmental events and in the pathogenesis of neuropsychiatric diseases [9]. These long ncRNAs are

\footnotetext{
* Correspondence: j.mattick@imb.uq.edu.au; mehler@aecom.yu.edu † Contributed equally

${ }^{1}$ Institute for Molecular Bioscience, University of Queensland, 306 Carmody Road, Brisbane, QLD 4072, Australia

${ }^{2}$ Institute for Brain Disorders and Neural Regeneration, Albert Einstein College of Medicine, Bronx, New York, NY 10461, USA
}

being shown to have a wide range of functions, including roles in the regulation of chromosomal architecture and dynamics, transcription, post-transcriptional processing, RNA editing, RNA trafficking and organelle biogenesis [4,10-14]. One major emergent function of long ncRNAs is their ability to modulate the epigenetic status of nearby protein-coding genes by recruiting chromatin activator or repressor complexes $[4,12,15]$.

Here we present the first systematic examination of long ncRNA expression profiles during differentiation of embryonic forebrain-derived neural stem cells (NSCs). We focused on a subset of cortical GABAergic neurons (GABANs) and oligodendrocytes (OLs) that are initially specified from sonic hedgehog (Shh)-responsive, $N k \times 2.1$ expressing bipotent neuronal-OL progenitor (N/OP) species within the ventromedial forebrain. We have previously reported that these N/OPs undergo long-distance 
tangential migration to cerebral cortex where they sequentially give rise to GABANs and OLs [16-21]. We employed custom designed microarrays to examine expression of noncoding and protein-coding transcripts during these neural developmental transitions, finding dynamic expression of ncRNAs associated with key neural development genes. We also observed differential expression of specific ncRNAs after treatment of oligodendrocyte progenitors (OLPs) with trichostatin A (TSA), a histone deacetylase (HDAC) inhibitor that prevents progression of OLPs into post-mitotic oligodendrocytes (PMOs) by suppressing oligodendrocyte-specific genes and inducing epigenetic reprogramming [22-26]. These developmental changes underscore the importance of epigenetic regulation in the elaboration of neural cell types and imply functional relationships between chromatin remodeling and selective deployment of ncRNAs.

\section{Results}

We conducted gene expression profiling using a customdesigned microarray platform to examine protein-coding and noncoding transcript expression accompanying neural stem cell-mediated fate restriction (bipotent progenitor cells: N/OPs), neural lineage specification (GABAergic neurons: GABANs and oligodendrocyte progenitors: OLPs), neuronal-glial fate switching (GABANs $\rightarrow$ OLPs), and neural lineage maturation (post-mitotic oligodendrocytes: PMOs and myelinating oligodendrocytes: MYOs) (Figure 1). In total, we found 31\% (4,616 out of 14,827 ) of probes targeting protein-coding transcripts exhibited expression above background and that $2366(16 \%)$ of these were significantly differentially expressed (B-statistic $>1$ ) at one or more developmental stages compared to NSCs [Additional file 1].

We found that $9 \%$ (332 out of 3,659) of probes targeting ncRNAs were expressed above background, of which 169 (5\%) were significantly differentially expressed (B-statistic $>1$; Figure 1) at one or more developmental stages compared to the NSC control (Additional file 2). These data reveal that a smaller percentage of ncRNAs are differentially expressed relative to protein-coding mRNAs. While this difference may be due to relatively poor annotation of the long noncoding transcriptome, it is consistent with previous reports in other developmental models $[1,27]$ and may reflect the fact that ncRNAs are primarily regulatory in nature requiring only subtle changes in expression to carry out their functional roles [28]. We also validated our microarray findings with QRT-PCR and found an $87 \%$ correlation between the gene expression profiles from the microarray data and QRT-PCR results [Additional file 3].

\section{Genomic analysis of expressed ncRNAs}

Long ncRNAs are often organized as part of complex interleaved transcriptional networks that include protein- coding genes $[1,2]$. A number of studies have shown that the association of long noncoding transcription with protein-coding genes has functional relevance, often with the ncRNA regulating expression of its protein-coding counterpart via epigenetic modifications and/or transcriptional co-activation/repression [14,15,29-31]. Therefore, we identified all ncRNAs expressed in our developmental models that are transcribed antisense to, bi-directionally, or from within the introns of overlapping or adjacent protein coding genes [Additional file 4]. In addition, we identified pairs of protein-coding RNAs and ncRNAs whose genomic loci are positionally conserved between mouse and human [Additional file 4] because this genomic conservation may also indicate a functional relationship between the two transcripts. In many cases, the associated protein-coding genes were critical neuro-developmental genes. As an illustrative example, the downregulation of a ncRNA (AK053922) is associated with the Gli3 locus in all progeny of N/OPs, whereas Gli3 was upregulated in N/OPs but downregulated in all progeny of N/OPs. This relationship may be of significant interest given that Gli3 has been shown to act as a bifunctional transcriptional switch that can either repress or activate Shh signaling [32] to help specify distinct neuronal cell types [33].

Many ncRNAs contain conserved secondary structures that are crucial to their function [34]. These conformational features may be bound by proteins [35], processed into smaller regulatory ncRNAs [36] or even fulfill intrinsic catalytic functions [37]. To provide support for the proposed functionality of the expressed ncRNAs, we looked for evidence of RNA secondary structures within differentially expressed ncRNA transcripts using the folding program RNAz [34]. We found 74 expressed ncRNAs that contained high confidence predicted conserved secondary structures (RNAz P >0.9) [Additional file 5] such as stem-loops [Additional file 6], known to be present in miRNA precursors, small nucleolar RNAs (snoRNAs) and other RNAs with previously characterized functions.

We then combined these genomic analyses to identify candidate ncRNAs for further functional analysis. These are discussed in more detail below in the context of neuronal and oligodendroglial lineage commitment, neuronal-glial lineage switching and progressive stages of oligodendrocyte lineage elaboration.

\section{Lineage restriction of neural stem cells (NSCs) into bipotent neuronal/oligodendrocyte progenitors (N/OPs)} A subset of nestin-immunoreactive NSCs within the ventral forebrain give rise to bipotent N/OPs following exposure to a gradient of Shh signaling $[17,20]$ which are characterized by expression of two bHLH transcription factors (Olig2 and Mash1) and their potential to 


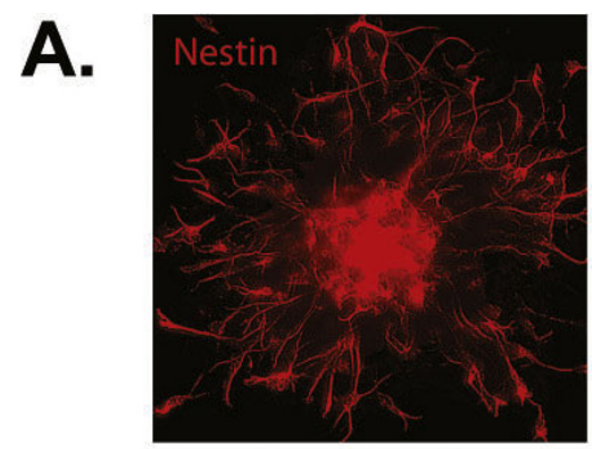

Neural Stem Cells (NSC)
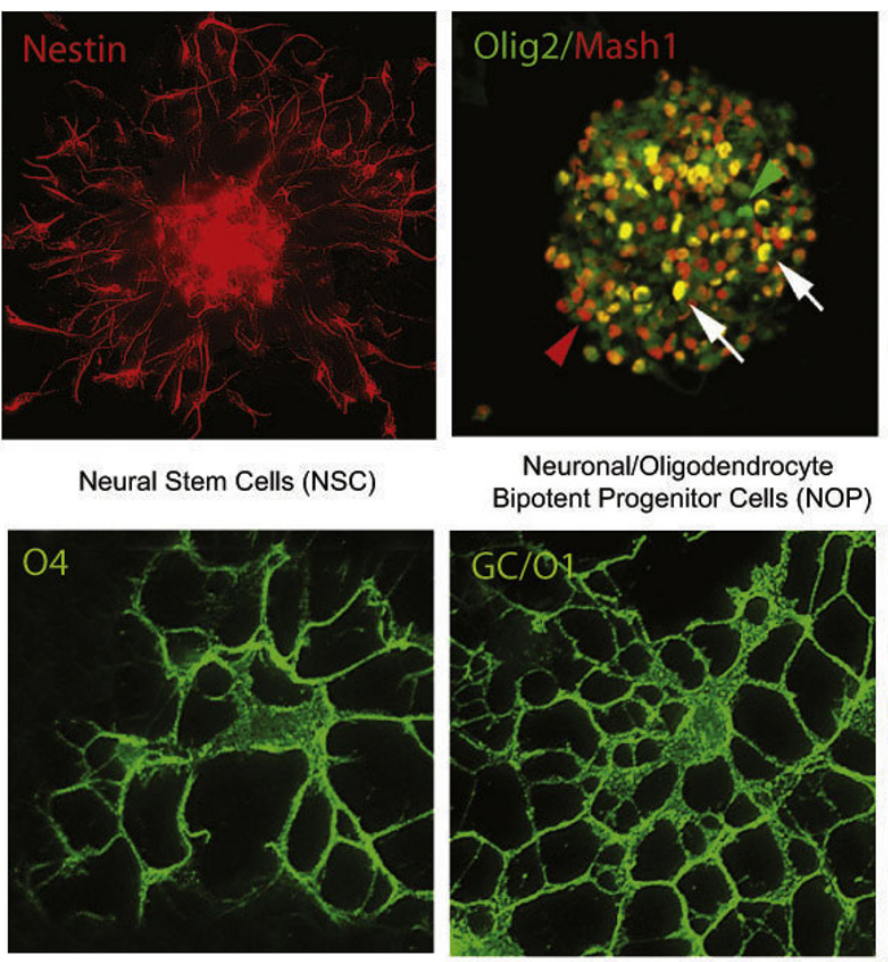

Neuronal/Oligodendrocyte Bipotent Progenitor Cells (NOP)
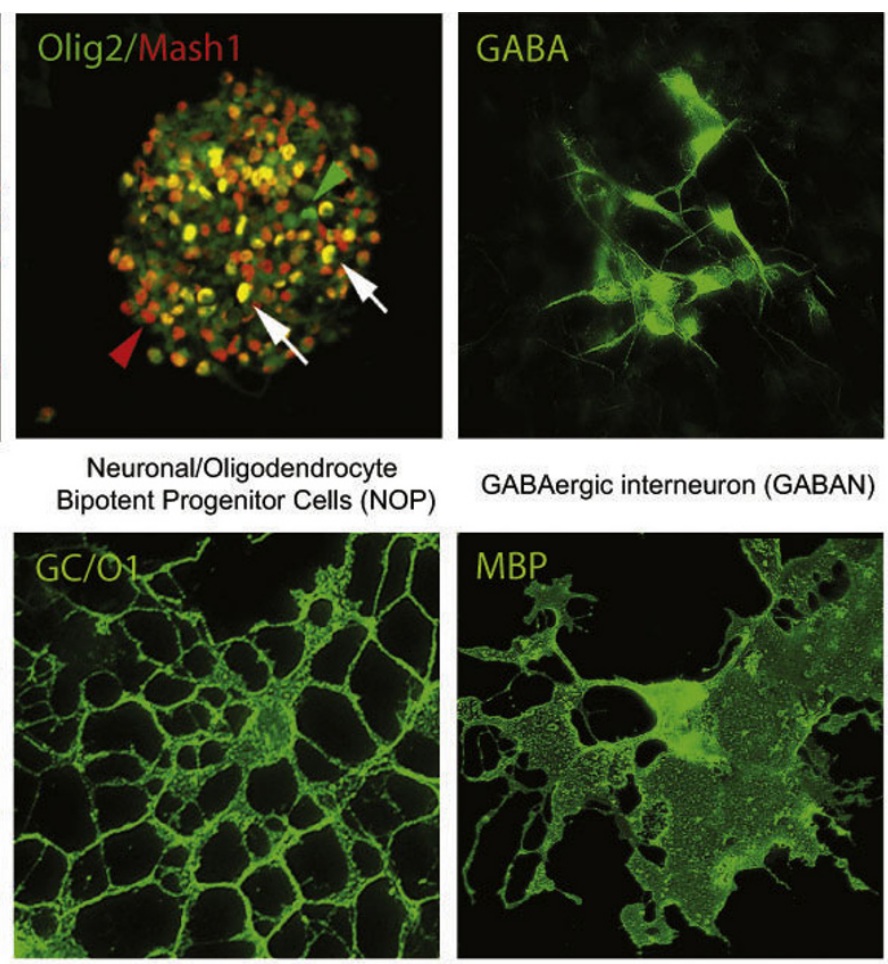

GABAergic interneuron (GABAN)

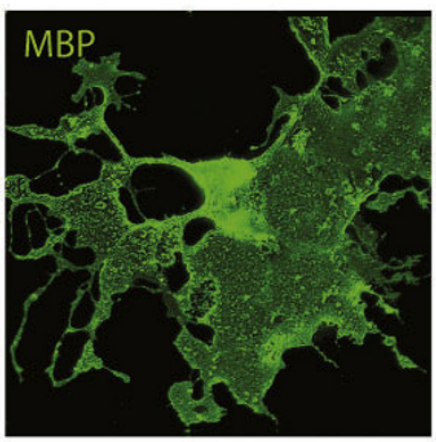

B.

Oligodendrocyte progenitor cells (OLP) Post-mitotic Oligodendrocytes (PMO) Myelinating Oligodendrocyte (MYO)

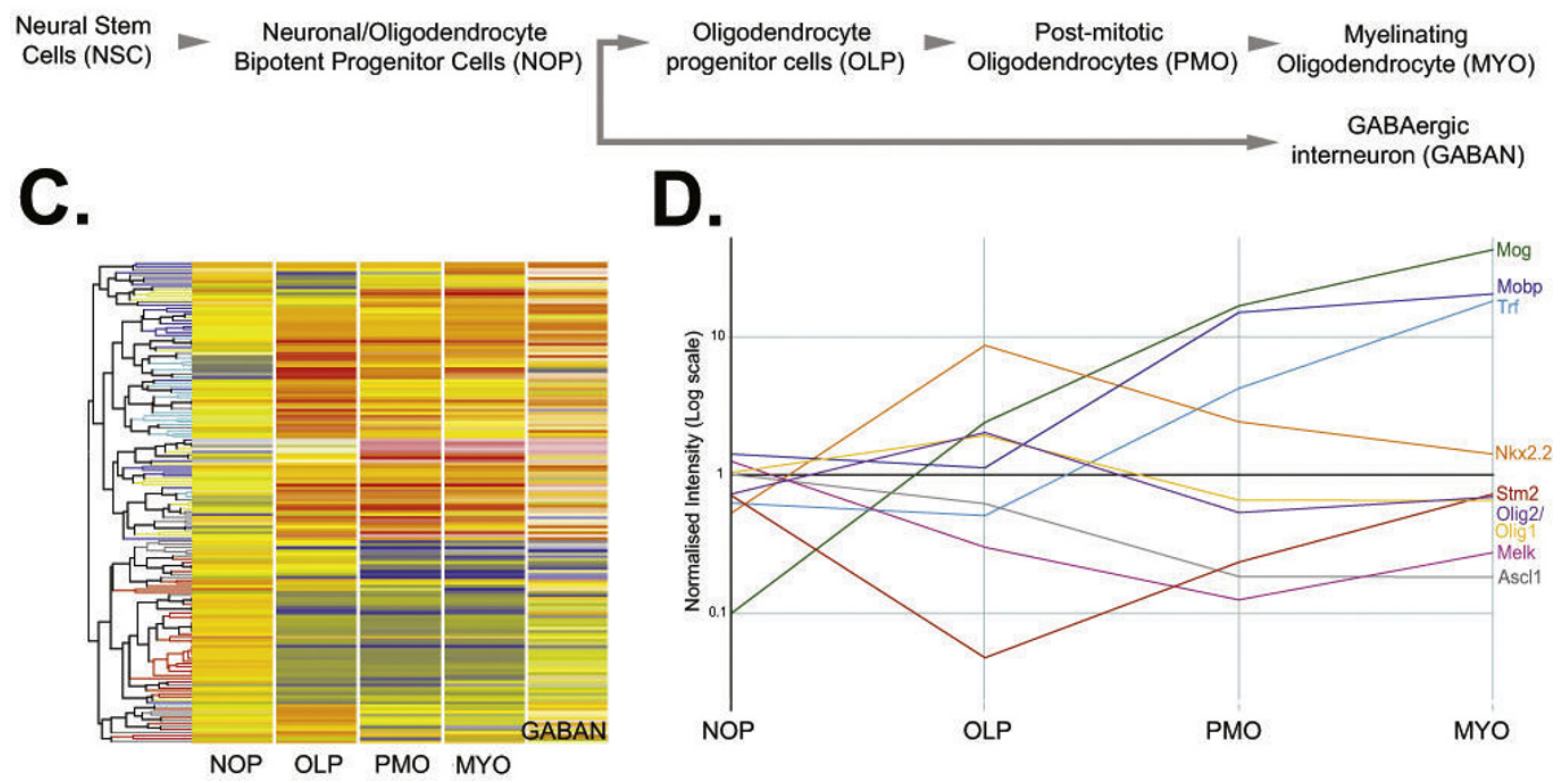

Figure 1 Profiles of gene expression during neural stem cell-mediated neural lineage elaboration. (A) Immunofluorescence micrographs of cellular expression patterns of lineage markers and bHLH transcription factors during progressive GABAergic neuronal and OL lineage elaboration from N/OPs: NSCs are labeled with nestin (TRITC) only, while N/OPs (white arrows) express both Olig2 (FITC, green arrow head) and Mash 1 (TRITC, red arrow head). GABANs expressed GABA (FITC). OLPs are stained with O4 (FITC), while PMOs and MYOs are identified by the expression of GC/O1 (FITC) and MBP (FITC), respectively. (B) Schematic flowchart illustrating the stages of oligodendrocyte and GABAergic neuron lineages analyzed within this study. (C) Tree-plot showing expressed ncRNAs clustered according to differential expression during microarray analysis. (D) Expression of mRNA marker genes with well characterized roles in GABAergic neuronal and progressive stages of OL lineage elaboration as determined by microarray. 
give rise to GABANs and OLs but not astrocytes $[16,20]$. Our microarray analysis revealed that the initial fate restriction of regional forebrain NSCs to bipotent N/OPs was associated with relatively modest changes in gene expression profiles, possibly reflecting the relative similarities between these developmental cell types. Nonetheless, there were differences in factors that may be important for promoting NSC lineage restriction and abrogating self-renewal and maintenance programs, including 65 upregulated and 167 downregulated mRNAs [Additional file 1]. Not surprisingly, some genes previously implicated in neurogenesis and gliogenesis exhibited dynamic changes in mRNA expression including transcription factors ( $52 \%$ of upregulated genes; $\mathrm{p}<$ 0.01 ) and cell-surface receptor linked signal transduction pathways $(21 \%$ of downregulated genes; $\mathrm{p}<0.01)$. For example, we found upregulated mRNAs included genes such as Mash1, an important transcription factor that promotes lineage restriction of NSCs into N/OPs [38-40].

We also identified dynamically expressed ncRNAs that may fulfill functional roles in NSC fate restriction. Similar to mRNAs, relatively few changes in ncRNA expression were observed during the transition from NSCs to N/OPs, with 17 ncRNAs exhibiting differential expression (8 upregulated and 9 downregulated) [Additional file 2]. These included a previously described ncRNA, Gomafu, shown to be localized to a novel subnuclear domain in a distinct subset of differentiating neurons in the mouse nervous system [41], which was exclusively downregulated in N/OPs but upregulated in all subsequent stages of OL lineage specification and maturation [Additional file 7]. Furthermore, in situ hybridization (ISH) in the adult mouse brain showed Gomafu expression in specific neuronal populations and nuclear localization within Purkinje cells [Additional file 7]. Our results show that Gomafu is not only expressed during neurogenesis but also during OL lineage specification.

A number of ncRNAs are significantly upregulated only during lineage restriction of NSCs, including the small nucleolar RNA (snoRNA) host gene 1 (Snhg1) and 10 (Snhg10), an expression profile supported by the restricted neuronal expression of Snhg10 in whole brain ISH [Additional file 8]. Snhg1 and Snhg10 host a group of $\mathrm{C} / \mathrm{D}$ box snoRNAs that serve as guides for the sitespecific 2'-O-methylation of ribosomal RNAs. Furthermore, two identified ncRNA species, Neat1 (also known as Men $\varepsilon / \beta$ ) and Neat2, are downregulated in N/OPs and broadly upregulated in their neuronal and glial progeny (Figure 2). Neat 1 and Neat 2 associate with nuclear paraspeckles and adjacent SC35 speckles, respectively; domains where transcription and co-transcriptional premRNA processing occur [42]. These nuclear domains have been associated with modulation of cell growth and differentiation $[43,44]$, and Neat1 $($ Men $\varepsilon / \beta)$ has been recently shown to be induced upon cell differentiation and to be required for the structural integrity of paraspeckles [45-47].

\section{Specification of GABAergic neurons (GABANs)}

Bipotent N/OPs can differentiate into either GABANs or OLPs in response to different neural cytokines [20]. We therefore examined changes in gene expression during the elaboration of GABANs to identify mRNAs and ncRNAs that may be involved in this type of neuronal lineage specification. We observed upregulation of 483 mRNAs, which were enriched for genes involved in nervous system development $(17.3 \%$; $\mathrm{p}<0.03)$, neuronal function $(9.88 \%, \mathrm{p}<0.05)$ and neurogenesis $(10.67 \%, \mathrm{p}$ $<0.05)$. We also identified 330 downregulated mRNAs [Additional file 1]. Interestingly, these downregulated mRNAs were enriched for predicted targets of let- $7 b$ $(13.2 \% \mathrm{p}<0.01)$ and mir-135 (11.3\%; p < 0.01), possibly being subject to repression by miRNAs. Indeed, both let- $7 b$ and mir-135 have previously been implicated in promoting neurogenesis $[48,49]$. In addition, we identified 56 ncRNAs that are upregulated during GABAN neurogenesis, including a number of examples such as Gtl2, Rian, Evf2, and Copg2as that were previously shown to exhibit neuron-enriched expression profiles in the adult mouse brain [6]. In contrast, we identified only 8 ncRNAs that were downregulated during GABAergic neurogenesis [Additional file 2].

We distinguished ncRNAs that may be involved specifically in GABAN lineage commitment by selecting ncRNAs upregulated during GABAN differentiation but downregulated during OL differentiation [Additional file 9]. We identified 4 ncRNAs, including an intergenic ncRNA transcript $A K 044422$ that overlaps a highly conserved brain-specific miRNA, miR-124a. MiR-124a accounts for nearly half of all brain miRNAs [50] (Figure 2 ) and helps to regulate neuronal specification and differentiation [51-53]. One mechanism by which miR-124 was shown to promote neuronal differentiation is by repression of Ptbp1, a negative regulator of alternative splicing, resulting in activation of neuron-specific alternative splicing events [53]. Indeed, we found that Ptbp1 and $A K 044422$ exhibited complementary expression profiles. However, the AK044422 transcript may itself function intrinsically as a full-length ncRNA, rather than simply acting as a precursor. The AK044422 transcript is subject to post-transcriptional modifications including splicing and polyadenylation, contains a number of high confidence predicted stem-loop structures (Fig 2.), and is highly conserved with homologous transcripts present in humans (AK091593, AL832535) and rats (BF402302). Indeed, the $A K 044422$ transcript was recently identified in a genome wide screen for functional lncRNAs, 


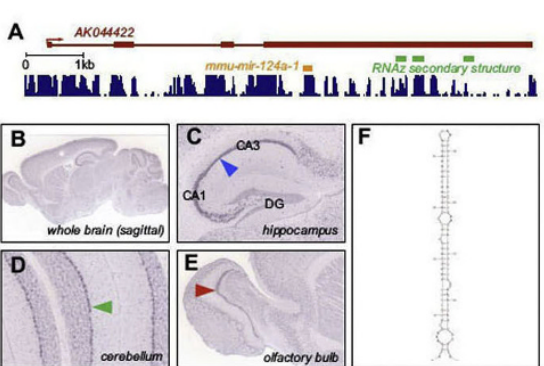

G

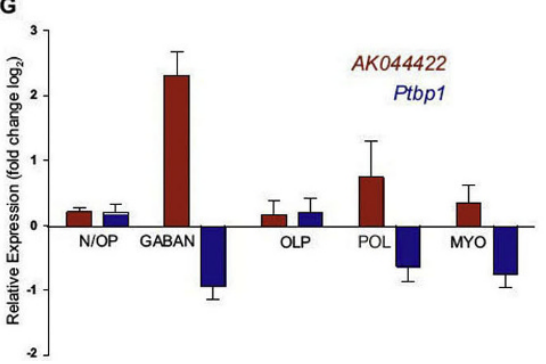

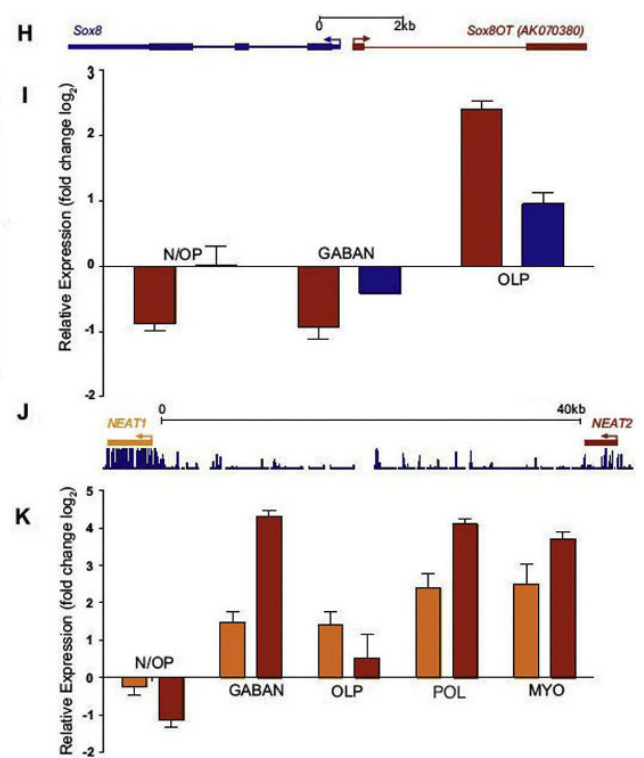

Figure 2 Detailed examples of ncRNAs expressed during oligodendrocyte differentiation. (A-F) Expression of the ncRNA AK044422 during GABAN and OL differentiation. (A) Genomic context of the ncRNA AK044422 transcript (red), miR-124a (orange), RNA secondary structures as predicted by RNAz [101] (green). (B-E) In situ hybridization of adult mouse brain sagittal sections for AK044422 transcript. (B) AK044422 is expressed broadly throughout the adult mouse brain. (C) AK044422 exhibits an enriched expression in the Cornu Ammonis subfields (CA1-3; blue arrow) (D) Detail of cerebellum shows AK044422 exhibits enriched expression in Purkinje neurons (green arrow). (E) Detail of olfactory bulb shows enriched expression in the mitral layer (red arrow). Images courtesy of (Allen Brain Atlas, http://brain-map.com). (F) Example of RNA secondary structure prediction within AK044422 transcript as rendered by CONTRAfold [99]. (G) Expression of AK044422 (red) and Ptbp1 (blue) according to microarray analysis (expression is relative to NSCs and error bars show standard deviation). (H) Genomic context of Sox8 (blue) and ncRNA Sox80T transcript (AK070380; red). (I) Expression of Sox80T (red) and Sox8 (blue) according to microarray analysis. (J) Genomic context of the ncRNAs Neat1 (orange) and Neat2 (dark red) and histogram of vertebrate conservation (dark blue). (K) Expression of Neat1 (orange) and Neat2 (red) according to microarray analysis.

termed lincRNAs, that exhibit a distinct chromatin signature indicative of transcriptional regulation and high levels of expression [54]. Furthermore, ISH in adult mouse brain revealed that the full-length AK044422 transcript is expressed in the mature central nervous system (Figure 2), suggesting an involvement in neurogenesis independent of mir-124a.

Because a large number of developmental gene-related enhancers have been shown to drive transcription in the developing forebrain during early neurogenesis [55], we examined ncRNAs expressed in GABANs that are associated with highly conserved enhancers. We identified 3 ncRNAs that were associated with highly conserved elements driving transcription in the forebrain [Additional file 10]. Two of these ncRNAs were associated with ultraconserved enhancers at the $D l x$ genomic loci, one of which, $E v f-2$, was previously shown to regulate binding of the Dlx2 transcription factor to the ultraconserved enhancer to activate the expression of the encompassed $D l x 6$ gene during neurogenesis [31].

We also identified a similar ncRNA antisense to the $D l x 1$ gene. Both $D l x 1$ and the antisense ncRNA, $D l x 1 A S$, are upregulated during GABAN differentiation but downregulated during OL differentiation [Additional file 10]. These observations are consistent with published data showing that $D l x 1$ and $D l \times 2$ promote GABAN lineage specification by suppressing the important oligogenic bHLH transcription factor, Olig2 [56] and are necessary for tangential migration of ventral forebrain-derived progenitor cells [17,56-58]. Dlx1AS is transcribed from an ultraconserved enhancer that drives expression in the midbrain, forebrain and olfactory system during development and in regions associated with neurogenesis in the adult mouse brain [7]. The third ncRNA, AK005755, which is also transcribed from an ultraconserved enhancer driving expression in the developing forebrain, has not been previously described and is not associated with any annotated developmental genes. Nonetheless, expression of this spliced transcript during GABAergic neurogenesis, coupled with its extremely conserved enhancer, suggests it plays a role in the developing forebrain.

\section{Specification of oligodendrocyte progenitors (OLPs)}

Application of PDGF-AA to N/OPs for 4 days in vitro was sufficient to promote the elaboration of OLPs (Figure 1B). We confirmed by immunofluorescence microscopy that N/OPs express the corresponding receptor 
(PDGFR $\alpha$ ) expression prior to and independent of the application of PDGF-AA [Additional file 11]. The developmental transition of N/OPs to OLs was associated with the upregulation of 665 mRNAs including a number of OL-selective genes, such as Olig1 and Olig2, and the downregulation of 650 mRNAs [Additional file 1]. We also found that 42 ncRNAs were downregulated, whereas 58 ncRNAs were upregulated, six of which exhibited highly correlated expression profiles to Olig1, having a distinct peak during OLP differentiation (Pearsons $\mathrm{R}^{2}>0.9$ ) [Additional file 12; Additional file 13].

To identify ncRNAs with specific roles in OL lineage commitment, we selected ncRNAs that were upregulated in OLPs but downregulated in GABANs. This analysis identified only one ncRNA, a novel $1.2 \mathrm{~kb}$ transcript (AK079380) organized bi-directionally to the Sox8 gene (Figure 2). Sox8 is a member of the SRY-box transcription factor family, many of which play key roles in OL lineage elaboration, including Sox 9 and Sox11 for OL specification and Sox 8 and Sox 10 for progressive OL maturation $[59,60]$. The ncRNA we identified, which we termed Sox8OT (Sox8 Opposite Transcript), exhibited concordant expression (Pearsons $\mathrm{R}^{2}>0.9$ ) to the Sox 8 mRNA. Furthermore, a positionally conserved homologous Sox8OT transcript is also present in humans (BC098409) and rats (BM382844), suggesting the bidirectional relationship between Sox 8 and Sox8OT is relevant. The bidirectional organization of the Sox8 gene and the Sox8OT ncRNA suggests that these transcripts are subject to common modes of regulation, possibly by sharing a promoter sequence. Indeed, recently published genome-wide maps of chromatin modifications [61] indicate a shared domain subject to dynamic modifications during the transition from embryonic stem to neuronal progenitor cells [Additional file 14]. Together, these data suggest Sox8OT functions in OL lineage commitment, possibly by regulating the expression of the associated $\operatorname{Sox} 8$ gene. As an alternative strategy to identify ncRNAs with specific roles in OL lineage commitment, we identified ncRNAs that were differentially expressed only in OLPs, and found that 16 were downregulated while 14 were upregulated including Dleu2, a previously described ncRNA overlapping but transcribed in the opposite direction of the Trim13 (RFP2/LEU5) gene whose expression is upregulated during early $\mathrm{OL}$ maturation and terminal differentiation [62].

\section{Progressive stages of OL lineage maturation including myelination}

The withdrawal of OL cytokines (PDGF-AA) from OLP culture conditions results in cell cycle exit (Figure 1A), though the actions of environmental factors such as triiodothyronine, cyclin dependent kinase inhibitors (CDKIs: $227^{\mathrm{KIP} 1}$ ), inhibitory HLH transcription factors
(ID4) and other transcription factors (YY1) that participate in the combinatorial molecular programs regulating this process [23,63-66]. In PMOs, we identified 768 upregulated mRNAs including genes involved in lipid metabolic processes $(11.4 \%, \mathrm{p}<0.02)$, such as $M b p$, a structural component of the myelin sheath [67]. We also observed downregulation of 562 mRNAs including genes involved in cell division $(32.7 \%, \mathrm{p}<0.01)$, mitosis (23.4\%, $\mathrm{p}<0.01)$, DNA replication $(13.8 \%, \mathrm{p}<0.01)$, and chromosome organization and biogenesis $(8.65 \%, \mathrm{p}$ $<0.01)$. Similarly, OLP cell cycle exit was accompanied by the upregulation of 38 ncRNAs and the downregulation of 26 ncRNAs. Many of the ncRNAs are associated with genomic loci encompassing protein-coding genes with previously described functions in development and maturation. For example, we found a highly conserved ncRNA, AK019302, hosted within the intron of Bai3, which was downregulated in PMOs. Bai3, which exhibits a similar expression profile, is a developmentally expressed angiostatic gene that is downregulated in the early phases of brain ischemia and in high-grade gliomas [68] and has been associated with mental retardation [69] and schizophrenia [70].

OL terminal differentiation is associated with the outgrowth of cytoplasmic processes and the accelerated production of myelin [71], and this process is regulated by neural cytokines, various classes of transcription factors, CDKIs (p21 ${ }^{\mathrm{CIP} 1}$ ), and epigenetic factors [72,73]. In MYOs, we found 733 upregulated mRNAs that were enriched for genes involved in lipid metabolic processes (8.7\%; $\mathrm{p}<0.01)$, biopolymer metabolic processes $(21.2 \%$, $\mathrm{p}<0.01)$, and actin cytoskeleton organization $(8.3 \%, \mathrm{p}<$ 0.01 ), including a dramatic increase in the expression of myelin genes such as $P l p 1, M b p$ and Mal. In addition, we found 51 ncRNAs that were upregulated during OL terminal differentiation and myelination, including 8 that were broadly upregulated during progressive stages of OL lineage elaboration, exhibiting a highly correlated (Pearsons $\mathrm{R}^{2}>0.9$ ) [Additional file 9; Additional file 12] expression profile with $\mathrm{Mog}$, an important glycoprotein found on the surface of MYOs [74]. In contrast, we found that 35 ncRNAs were downregulated, including 27 ncRNAs that exhibited a highly correlated expression profile (Pearsons $\mathrm{R}^{2}>0.9$ ) [Additional file 12; Additional file 13] to Melk, a factor important for promoting NSC proliferation $[1,75]$ that was downregulated during OL lineage elaboration.

A variety of ncRNAs were broadly upregulated in OLPs, PMOs and MYOs including AK141895 and $A K 133808$, associated with the Slc44a1 and Rab11b genomic loci, respectively. In these cases, both the ncRNAs and the protein-coding transcripts were strongly upregulated during OL lineage elaboration suggesting that they may function coordinately to promote 
appropriate OL maturation and expression of myelin proteins. We similarly identified a ncRNA antisense to Ecsit, an important node between BMP and Toll-Like Receptor (TLR) pathways that integrates morphogenetic signaling with pathogen recognition and innate immunity during development [76,77]. The ncRNA, $A K 050588$, is upregulated in GABANs, OLPs and MYOs, in contrast to Ecsit, which is downregulated in these species. The observed inverse expression pattern between AK050588 and Ecsit is similar to a correlation we recently observed in embryonic stem cell differentiation [7] and suggests coordination between the expression profiles of this pair of transcripts.

\section{Epigenetic reprogramming of cell fate with trichostatin A (TSA)}

Histone deacetylation has been implicated in modulating OL lineage progression, particularly for developmental species undergoing cell cycle exit and progressive stages of cellular differentiation characterized by the acquisition of a branched morphology and the onset of myelin gene expression [25]. Treatment with TSA, an HDAC inhibitor, prevents progression of OLPs into PMOs with the resulting preservation of a simplified morphological phenotype that does not display secondary branching characteristic of differentiating PMOs (Figure 3). The inhibition of HDAC suppresses OL-specific gene expression and reprograms these cells into a less lineage committed state receptive to neurogenic or gliogenic differentiation signals [22-24,26,78-81]. Given that we observed a number of ncRNAs exhibiting specific expression profiles during OL lineage progression, we were interested to examine whether their expression was similarly regulated by histone deacetylation. Changes to ncRNA expression in response to HDAC inhibition would suggest the incorporation of these ncRNAs within a genetic program that contributes to progression of either neuronal or oligodendrocyte differentiation.

We employed QRT-PCR to examine the expression of ncRNAs identified within this study as strong candidates for functional roles in OL or neuronal differentiation. Broadly, we found parallel changes in cellular phenotype and alterations in ncRNA expression profiles induced by TSA. In addition to examples described above, we included other ncRNAs associated with neural developmental genes that exhibited representative developmental expression profiles. Almost all selected ncRNAs (14 of 15) exhibited significant $(\mathrm{p}<0.05)$ changes in expression at 24 or $48 \mathrm{~h}$ (Figure 3 ). The majority of these changes were sustained or developed during later stages (i.e., at $48 \mathrm{~h}$ ), suggesting the expression of these ncRNAs is subject to regulation by mechanisms of histone deacetylation.
While we observed both increased and decreased expression of long ncRNAs, the majority was downregulated, often dramatically, supporting the putative role of these ncRNAs in contributing to the progressive differentiation of OLs (Figure 3). Downregulated ncRNAs included those associated with protein-coding genes involved in progressive OL differentiation. In addition to those previously described including Sox8OT, Gomafu, AK014263 (hosted in an intron of Csmd1) and AK019302 (hosted in an intron of Bai3), we also observed dramatic downregulation of ncRNA AK020939 which is hosted within an intron of Lhfpl3, a member of the tetraspanin proteins which promote proliferation, migration and differentiation of OLs $[82,83]$.

Recent evidence has shown that histone deacetylation is responsible for restricting neuronal gene expression, with the inhibition of HDACs inducing neuronal differentiation [84]. Therefore, it is of interest that a number of candidate ncRNAs exhibit an increase in expression in response to HDAC inhibition, possibly suggesting a contribution to neuronal rather than OL differentiation. For example, the previously described ncRNA Gtl2 was upregulated after TSA treatment. Indeed, within his study we observed upregulation of Gtl2 during GABAN differentiation. Gtl2 is expressed in restricted domains of the developing forebrain including ventral telencephalon, neocortex, hippocampus and diencephalon, suggesting roles in regional neuronal development and differentiation [85]. Finally, we found that Neat1 transcription exhibited complex transcriptional dynamics after TSA treatment, being strongly upregulated after TSA treatment under stochastic (probabilistic) oligodendroglial specification conditions, whereas it was downregulated after TSA treatment under the influence of instructive (inductive) signals for OL lineage elaboration (see Methods; Figure 3 and Additional file 15).

\section{Discussion}

In this study, we utilized a custom-designed microarray platform to probe the transcription of both protein-coding and noncoding transcripts during ventral forebrainderived NSC lineage restriction, neuronal and oligodendrocyte (OL) lineage specification, neuronal-glial fate transitions, and progressive stages of OL lineage elaboration including myelination. Expression profiles for mRNAs in our study were similar to previously reported findings $[62,86]$ showing modulation of key signaling pathways, transcription factors, and epigenetic regulators that help to define the molecular codes governing neural lineage elaboration. Additionally, we also observed expression of components of the myelin sheath.

Although we examined protein-coding genes, we focused primarily on characterizing the expression profiles of long ncRNAs, which are being increasingly 

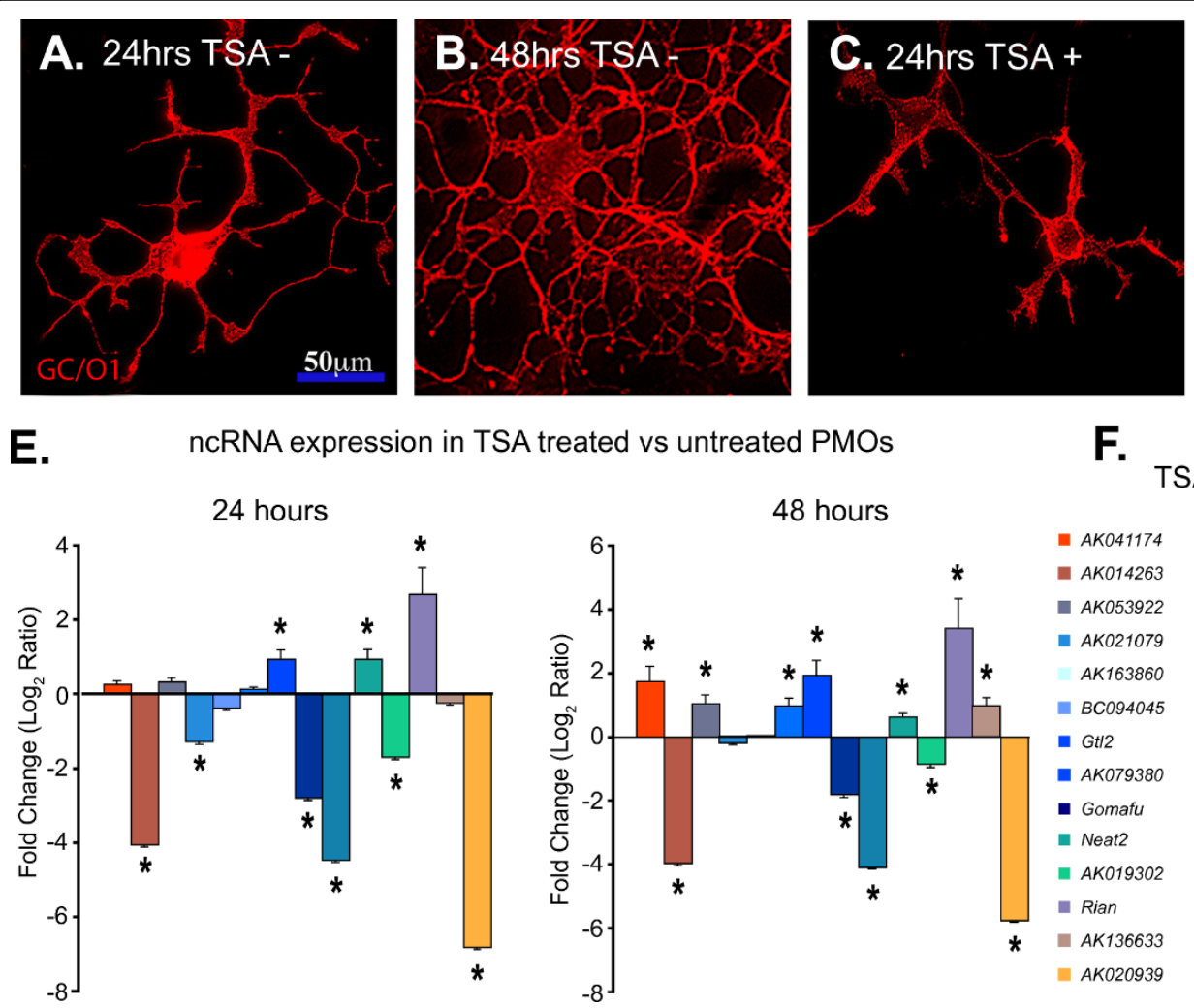

F. Neat1 expression following TSA treatment under instructive

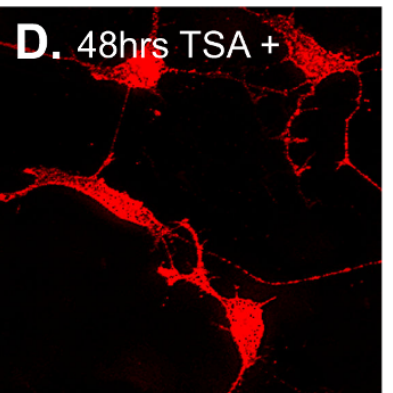

Figure 3 The HDAC inhibitor, TSA prevents the acquisition of secondary morphological features of differentiating PMOs with concurrent alteration in the expression profiles of ncRNAs. (A-D) Immunofluorescence micrographs demonstrating the profiles of $O L$ lineage species in the absence (A, B) or presence of TSA (C, D) at $24 \mathrm{~h}$ and $48 \mathrm{~h}$. (E) The fold change in ncRNA expression in TSA treated versus untreated PMOs at $24 \mathrm{~h}$ and $48 \mathrm{~h}$. (F) The fold change in Neat1 expression in TSA treated versus untreated PMOs under CNTF presence (instructive) or absence (stochastic) with concurrent PDGF-AA factor withdrawal. Immunofluorescence micrographs of CNTF naïve, TSA treated cells and fold-change as determined by Q-PCR for remaining ncRNAs is illustrated in Additional file 15. (Error bars indicate standard error with asterisks indicated significant fold change at $p>0.05$ ).

appreciated in the regulation of developmental gene expression programs [3,4,7,28]. Previous studies of neural differentiation have reported expression profiles for only a small number of long ncRNAs, such as $N k \times 2.2 A S$ and the imprinted $H 19$ ncRNA $[62,86,87]$. In contrast, we examined a large spectrum of long ncRNAs and found dramatic changes in expression that are unique to specific stages of cellular differentiation. Many of these ncRNAs are transcribed from complex genomic loci that encompass protein-coding genes with defined roles in neuronal and glial lineage elaboration, and these pairs of ncRNAs and associated protein-coding genes often exhibited coordinated expression during developmental transitions. Therefore, we suggest that these ncRNAs may influence the expression of the associated protein-coding genes similar to previously characterized examples such as $N k x 2.2 A S$ [87], HOTAIR [29], p15AS [30], p21AS [15] and Evf2 [31]. For example, many ncRNAs were associated with transcription factors that were themselves differentially regulated during OL differentiation $[62,86]$. Long ncRNAs, such as those identified in this study, may therefore contribute to the combinatorial transcriptional codes involved in lineage specification and terminal differentiation including myelination.

The coordinated expression of long ncRNAs with critical neural developmental protein coding genes suggests that both are subject to shared regulatory mechanisms and that long ncRNAs are integrated into complex environmentally-mediated neural and glial developmental gene expression programs. We, therefore, considered whether the well-documented ability of epigenetic mechanisms to promote decisive changes in neuronal and glial gene expression programs also includes the capacity to regulate long ncRNA expression. Indeed, treatment with the HDAC inhibitor, TSA, effectively arrests the developmental progression of OLPs into PMOs [23] and also affects the expression of long ncRNAs, suggesting that these are not only regulated by epigenetic modifications but also these transcripts are incorporated into a broader lineage specific developmental gene expression program. Furthermore, HDAC 
inhibition also has differential effects on certain ncRNAs in an environmentally responsive manner. For example, treatment of OLPs with TSA in the presence (inductive) or absence (stochastic) of CNTF results in opposing profiles of Neat1 expression, implying that long ncRNAs might be deployed in a context-specific manner to dynamically modulate seminal fate decisions within the $\mathrm{OL}$ lineage. Although the use of HDAC inhibitors has been essential for interrogating the epigenetic mechanisms that govern OL lineage maturation, the cellular effects of TSA administration are complex and our understanding of the mechanisms mediating ncRNA expression are still evolving. Nonetheless, long ncRNAs may represent important targets for regenerative therapies in the CNS because they exhibit both exquisite site-selective as well as genome wide effects $[5,13]$ associated with dynamic OL developmental transition states characterized by considerable epigenetic flux [22-24,26,78,79,81].

\section{Conclusions}

This study is the first systematic examination of the expression of long ncRNAs in forebrain-mediated NSC maturational processes, specifically OL differentiation and development. It is also the first demonstration that long ncRNAs, many of which are involved in regulating epigenetic processes, are also themselves subject to regulation by epigenetic processes. It adds to a growing consensus that not only are large portions of the mammalian genome transcribed [27] but also expressed in a regulated manner [7]. The specific expression of ncRNAs has been recently observed in other developmental programs and comparisons between these studies reveal both common and unique features $[7,88]$. Because the long noncoding transcriptome is still relatively poorly annotated and only partially interrogated by this study, it seems likely that many more long ncRNAs will be shown to be expressed during development and their importance for neuronal and glial biology will be more fully understood and appreciated. These studies will have particular relevance in the future as the role of noncoding transcripts in neurological disease states becomes increasingly recognized [89].

\section{Methods}

Neural stem cell cultures

Early embryonic (E14) multipotent and more lineagerestricted progenitor species derived from the ventral forebrain were plated at clonal density $(1000$ cells $/ \mathrm{mL})$ and propagated in serum free media (SFM) containing specified factors for various time intervals, and subsequently examined by immunofluorescence microscopy to define neural lineage profiles, expression of selected transcription factors (Figure 1) and to detect cellular proliferation (BrdU, $10 \mu \mathrm{M}$, added $3 \mathrm{~h}$ prior to fixation) as previously described [20,90-92]. Multipotent progenitor clones were generated by application of basic fibroblast growth factor (bFGF, $10 \mathrm{ng} / \mathrm{mL}$ ) and were cultured 7 days in vitro (DIV) and were passaged twice to enrich the self-renewing NCSs. Subsequently, NSC clones were dissociated by trypsinization and were exposed to bFGF and the N-terminal active form of Shh (N-Shh, $50 \mathrm{ng} /$ $\mathrm{ml}$ ) for $2 \mathrm{DIV}$ to generate N/OP clones [20]. GABANs were generated from N/OPs by the application of BMP2 $(10 \mathrm{ng} / \mathrm{mL})$ for $2 \mathrm{DIV}$. OLPs were generated from $\mathrm{N} /$ OPs by the application of PDGF AA $(10 \mathrm{ng} / \mathrm{mL})$ for 4 DIV [Additional file 11] [20,71]. PMOs and MYOs were generated from on 6 DIV late-stage OLPs by withdrawal of PDGF and concurrent addition of CNTF $(20 \mathrm{ng} / \mathrm{mL})$ for an additional 2 DIV and 4 DIV respectively [65,71]. We followed institutional IACUC guidelines for experiments in which primary mouse tissue specimens were used (Einstein Institute for Animal Studies protocol \# 20080709).

\section{Trichostatin A (TSA) treatment}

The application of TSA (10 ng/mL, Sigma) to OLs was done at the time of withdrawal of PDGF in the presence (inductive oligodendrogliogenesis) or absence (stochastic oligodendrogliogenesis) of CNTF that is necessary to promote cell cycle exit and OL differentiation. In addition to study of the four developmental stages encompassing oligodendrogliogenesis (N/OPs $\rightarrow$ OLPs $\rightarrow$ PMOs $\rightarrow$ MYOs), we also analyzed the expression patterns of selected ncRNAs at the time of PDGF withdrawal without CNTF or TSA addition $\left(\mathrm{T}_{0}\right)$, and at $24 \mathrm{~h}$ and $48 \mathrm{~h}$ after TSA treatment in the presence and absence of CNTF [72,93]. We also compared these values to data obtained from OLs not treated with TSA at $24 \mathrm{~h}$ and at $48 \mathrm{~h}$ [25].

\section{Immunofluorescence microscopic analysis}

This analysis was performed as previously described [72,93].

\section{Antibody preparations}

Antibodies against the neuroepithelial marker, nestin (mIgG1, 1:200, Pharmingen) were used to label both NSCs and N/OPs. N/OPs were distinguished from NSCs by the expression of the bHLH factors, Olig2 (goat IgG, 1:500, R\&D) and Mash1 (mouse, mIgG1, 1:250, Pharmingen). Progressive stages of OL lineage elaboration were documented by the expression of the OL progenitor marker, O4 (mIgM, 1:600 Sigma), the PMO marker, GC/O1 (mIgM, 1:300 Chemicon) and the MYO marker, MBP (mIgG2b, 1:500 Sternberger Monoclonals Inc.). GABANs were identified by immunoreactivity against GABA (rabbit IgG, 1:1000 Sigma). Expression of PDGFR $\alpha$ on N/OPs was assessed using an antibody 
against PDGFR $\alpha$ (goat IgG, 1:300, R\&D Systems). Nuclear and cell cycle-associated reagents (BrdU, mIgG1, 1:400, Novocastra; Hoechst 33342, $2 \mu \mathrm{g} / \mathrm{mL}$ ) were utilized to assess cell proliferation.

\section{Growth factors}

To generate the various neural stem, progenitor and more lineage-restricted neuronal and OL lineage species required for immunocytochemical analysis, the following growth factor preparations were utilized: recombinant bFGF (Collaborative Biomedical Products), N-Shh, PDGF-AA and CNTF (R\&D Systems) and BMP2 (gift from Genetics Institute).

\section{RNA preparations}

RNA from mouse tissues and cell cultures was purified using Trizol (Invitrogen) or RNeasy Mini Kit (Qiagen) and treated with DNase I (Invitrogen), according to the protocols provided by the manufacturers. The quality of purified total RNA samples was assessed with an RNA 6000 Nano assay kit using the Agilent 2100 Bioanalyzer (Agilent Technologies) according to the manufacturer's instructions. For microarray experiments, RNA was amplified and labeled using the Amino Allyl Message Amp II kit (Ambion) following the instructions provided by the manufacturer. Amplified aRNA from each time point, as well as a reference pooled sample comprising a mixture of RNA from all time points, was labeled with either $\mathrm{Cy} 3$ or $\mathrm{Cy} 5$ monoreactive dyes (Amersham Biosciences) according to the MessageAmp II protocol (Ambion). The quality and quantity of amplified RNA samples were assessed using the Agilent 2100 Bioanalyzer as described above.

\section{Microarray expression profiling}

The microarrays contained 22,038 65-mer oligonucleotide probes from the Mouse OligoLibrary (Compugen, San Jose, CA, USA) and 2,118 70-mer oligonucleotide probes that were designed to target ncRNAs, including known mouse pre-miRNAs from miRBase [94], longer mouse ncRNAs from RNAdb [1], and "high confidence" ncRNAs identified from the FANTOM3 project [1]. The custom 70-mer probes were printed alongside Mouse OligoLibrary probes on Power Matrix slides (Full Moon BioSystems, Sunnyvale, CA, USA) at the SRC Microarray Facility (University of Queensland, Brisbane, Australia). The quality of the print run was verified by hybridizing random 10-mer oligonucleotides to the $1^{\text {st }}$ and last slides of the run. The array design is available from the ArrayExpress Data Warehouse (EMBL-EBI; ArrayExpress Accession Number A-MEXP-1070).

Labeled RNAs from each of the five developmental stages was hybridized with the NSC sample to individual microarrays. Three biological replicates were performed for each time point. Blocking, hybridization and washing was performed according to the manufacturer's instructions (Full Moon BioSystems, Sunnyvale, CA, USA). Slides were scanned at $5 \mu \mathrm{m}$ resolution using a DNA microarray scanner (Agilent Technologies). Feature extraction was performed using ImaGene software (BioDiscovery, El Segundo, CA, USA), with manual grid adjustment and auto-spot finding and segmentation. Data was exported from ImaGene as text files, then uploaded and analyzed using the Linear Models for Microarray Data (LIMMA) software package via the $\mathrm{R}$ Project for Statistical Computing http://www.r-project. org. Data was background-corrected, normalized both within and between arrays [95], and differential expression analysis was performed by fitting a linear model of the data to the experimental design matrix and then calculating Bayesian statistics (B statistics; posterior log odds) adjusted for multiple testing using BenjaminiHochberg analysis [96]. Raw and processed microarray data is available at the ArrayExpress Data Warehouse (EMBL-EBI; ArrayExpress Accession Number E-TABM874).

\section{PCR primers}

The primers were designed and synthesized (Invitrogen) to amplify selected ncRNA sequences [Additional file $16]$.

\section{Quantitative real-time PCR}

Quantitative real-time PCR (QRT-PCR) was performed according to manufacturer's protocols (Qiagen). QRTPCR reactions were performed in a 96-well plate, each reaction consisted of a $25 \mu \mathrm{L}$ mixture including $12.5 \mu \mathrm{L}$ of 2× QuantiFast SYBR Green PCR Master Mix (Qiagen), $1 \mu \mathrm{M}$ of forward and reverse sequences of the corresponding primers and $40 \mathrm{ng}$ of cDNA. Mouse $18 \mathrm{~S}$ ribosomal RNA was used as an internal control to ensure accuracy of the results. QRT-PCR amplifications were performed using the ABI PRISM 7000 Sequence Detection System (Applied Biosystems). Amplification conditions were as follows: $5 \mathrm{~min}$ at $95^{\circ} \mathrm{C}$ to activate the HotStarTaq Plus DNA Polymerase followed by 40 cycles of $10 \mathrm{~s}$ at $95^{\circ} \mathrm{C}$ and $30 \mathrm{~s} 60^{\circ} \mathrm{C}$. QRT-PCR conditions were optimized by adjusting the primer concentrations and the quantity of cDNA. A dissociation curve was performed to ensure the validity of each specific PCR product. QRT-PCR results were analyzed using Relative Expression Software Tool [97] software http://rest.genequantification.info/.

\section{Classification of probes targeting protein-coding or non- protein-coding transcripts}

Although the Mouse OligoLibrary probe set was predominantly designed to recognize known or putative 
protein-coding transcripts, several thousand probes targeted miscellaneous cDNAs and ESTs whose coding status was not well characterized at the time this commercial probe set was first produced. To update the annotation of these probes and to clarify whether they targeted protein-coding or noncoding regions, a computational pipeline was designed to re-annotate the entire probe set. Sequences for all probes were mapped to the February 2006 (NCBI Build 36) assembly of the mouse genome using BLAT [98] (parameters: $\operatorname{minScore}=50$, minIdentity $=99$, stepSize $=5$, tileSize $=11$, ooc $=11$. ooc). Probes that could not be reliably mapped were excluded from the study. Targeted transcripts were then defined as protein-coding and noncoding as described previously [7]. The genomic context of ncRNAs (relative to protein-coding genes) was also determined as described previously [6].

\section{Conservation and secondary structure predictions of ncRNAs}

The secondary structural composition of expressed ncRNAs was determined by intersecting their chromosomal positions with those of the RNAz structural predictions made across the entire mouse genome (using confidence threshold levels of $\mathrm{P}>0.5$ and $\mathrm{P}>0.9$ ), which were performed as previously described $[6,34]$. High confidence predicted RNA secondary structures were rendered with CONTRAfold [99].

\section{Gene Ontology (GO) term and microRNA target enrichment analysis}

The Gene Ontology project http://www.geneontology. org/ provides a controlled vocabulary to functionally annotate genes. By studying GO terms associated with a large set of genes, one obtains useful information about the types of genes represented. Lists of differentially expressed protein-coding genes were uploaded into FastiGO+ http://babelomics.bioinfo.cipf.es[100]. Statistically over-represented GO terms in the biological process and molecular function and microRNA target enrichments were obtained by applying a p-value cutoff as indicated, correcting for multiple testing with Benjamini False Discovery Rate.

Additional file 1: Expression of mRNAs according to microarray analysis at different stages of oligodendrocyte and neuronal differentiation. Abbreviations are: bipotent progenitor cells, N/OP; GABAergic neurons, GABAN; oligodendrocyte progenitors, OLP; postmitotic oligodendrocytes, PMO; myelinating oligodendrocytes: MYO). Probe IDs for targeted mRNA may be queried in the NRED database [102]. Information for targeted mRNAs shown includes Accession IDs, UniGene Common Name and Symbol and M-statistic, Fold Change, Aand B-statistic as calculated from microarray analysis.

Click here for file

[http://www.biomedcentral.com/content/supplementary/1471-2202-1114-S1.XLS]
Additional file 2: Expression of ncRNAs according to microarray analysis at different stages of oligodendrocyte and neuronal differentiation. Abbreviations are: bipotent progenitor cells, N/OP; GABAergic neurons, GABAN; oligodendrocyte progenitors, OLP; postmitotic oligodendrocytes, PMO; myelinating oligodendrocytes: MYO). Probe IDs for targeted mRNA may be queried in the NRED database [102]. Information for targeted ncRNAs shown includes Accession IDs, Mstatistic, Fold Change, A- and B-statistic as calculated from microarray analysis.

Click here for file

[http://www.biomedcentral.com/content/supplementary/1471-2202-1114-S2.XLS ]

Additional file 3: QRT-PCR validation for microarray analysis of ncRNA expression in OL lineage elaboration. QRT-PCR analysis was performed to evaluate expression of 11 ncRNA across five cell types and corroborated microarray data in 48 (87\%) of 55 instances.

Click here for file

[http://www.biomedcentral.com/content/supplementary/1471-2202-1114-S3.XLS ]

Additional file 4: Noncoding RNAs associated with protein-coding genes. Noncoding transcript accession IDs are shown with associated protein-coding UniGene Common Name and Symbol and relationship of association (intronic, bidirectional, antisense). Evidence for positional conservation of ncRNA with homologous gene in the human genome (hg18) indicated.

Click here for file

[http://www.biomedcentral.com/content/supplementary/1471-2202-1114-S4.XLS ]

Additional file 5: Noncoding RNA transcripts sequences predicted to fold into high confidence $(P>0.9)$ secondary structures according to RNAz. Chromosome coordinates and sequences are provided for region of expressed ncRNAs that are predicted to fold into conserved secondary structures. Predicted secondary structures according are provided in dot-bracket annotation (analysis conducted with Vienna RNA Package [101]). Selected high confidence structures are illustrated in Additional file 6.

Click here for file

[http://www.biomedcentral.com/content/supplementary/1471-2202-1114-S5.XLS]

Additional file 6: Rendered illustrations of the top five most stable secondary predicted structures in expressed ncRNAs. The five most predicted stable structures were rendered using CONTRAfold [99]. Click here for file

[http://www.biomedcentral.com/content/supplementary/1471-2202-1114-S6.PDF ]

Additional file 7: Gomafu expression during GABAergic neuronal and progressive stages of $\mathrm{OL}$ lineage elaboration. (A) Relative expression of Gomafu during GABAN and OL differentiation (expression is relative to NSCs and error bars show standard deviation). Gomafu is exclusively downregulated in N/OPs, but upregulated in all other sampled cell stages. (B) In situ hybridization of sagittal adult mouse brain sections for Gomafu expression. Whole brain is shown in top left panel, hippocampus top right panel, coronal section of olfactory bulb in bottom left panel, and sagittal section of olfactory bulb and cortex in bottom right panel. Gomafu is expressed in the cortex (green arrow), hippocampus and mitral layer of the olfactory bulb (red arrow). Gomafu does not exhibit expression in the cerebellum (blue arrow). Images courtesy of the Allen Brain Atlas http://www.brain-map.org.

Click here for file

[http://www.biomedcentral.com/content/supplementary/1471-2202-1114-S7.PDF ]

Additional file 8: Snhg10 exhibits specific expression profiles in the adult mouse brain. Snhg10 exhibits a strong and broad expression throughout the whole mouse brain (A), with specific expression in Purkinje cells in the cerebellum (B) and hippocampus (C). Images courtesy of the Allen Brain Atlas http://www.brain-map.org.

Click here for file

[http://www.biomedcentral.com/content/supplementary/1471-2202-1114-S8.PDF ] 
Additional file 9: mRNAs and ncRNAs that exhibit discordant expression trends during neuronal-glia fate switching. Table shows probe IDs that may be queried in the NRED database (Dinger et al., 2008), UniGene Common Name and Accession IDs and the discordant M-statistic and fold change associated with neural stem cell to GABAergic neuron (GABAN vs NSC) or oligodendrocyte progenitor (OLP vs NSC) transition as determined by microarray analysis.

Click here for file

[http://www.biomedcentral.com/content/supplementary/1471-2202-1114-S9.XLS ]

Additional file 10: Expression of ncRNAs associated with ultraconserved elements. (A) Genomic context of the $D / x 1$ and $D / x 2$ gene (dark blue), the ncRNA DIX1AS (AK132348; red) showing the position of ultraconserved element with previously described enhancer function (VISTA 422; green) and histogram of vertebrate conservation (dark blue). (B) Enhancer (VISTA 422) function driving reporter gene expression in the developing forebrain (red arrow) of 11.5 day mouse embryo [55]. Images courtesy of VISTA Enhancer Browser http://enhancer. Ibl.gov/frnt_page.shtml. (C) Expression of D/xiAS (red) and D/x1 gene (blue) during OL differentiation (expression is relative to NSCs and error bars show standard deviation). DIX1AS ncRNA is upregulated in GABAN, similar to $D / x 1$, but downregulated in N/OPs and in different stages of $O L$ differentiation (OLPs, PMOs, MYOs). (D) Genomic context of the D/x5 and D/x6 genes (blue) and the ncRNA Evf transcripts (1 and 2; red) showing the position of two ultraconserved elements with previously described enhancer function (VISTA 298) [55] and the enhancer described by Feng et al. [31]; green) and histogram of vertebrate conservation (dark blue). (E) Enhancer (VISTA 298) function driving reporter gene expression in the developing forebrain (red arrow) of 11.5 day mouse embryo [55]. Images courtesy of VISTA Enhancer Browser http://enhancer.lbl.gov/frnt_page. shtml. (F) Expression of Evf (red) and D/x5 gene (blue) during oligodendrogliogenesis (expression is relative to NSCs and error bars show standard deviation). The Evf ncRNA (red) is upregulated during GABAN, similar to D/x5 (blue), but downregulated in N/OPs and later stages of oligodendrogliogenesis (OLPs, PMOs, MYOs). (G) Genomic context of the novel AK005755 ncRNA (red) showing the position of; ultraconserved element with previously described enhancer function (VISTA 433; green) and histogram of vertebrate conservation (dark blue). (H) Enhancer (VISTA 433) function driving reporter gene expression in the developing forebrain (red arrow) of 11.5 day mouse embryo [55]. Images courtesy of VISTA Enhancer Browser http://enhancer.lbl.gov/frnt_page. shtml.

Click here for file

[http://www.biomedcentral.com/content/supplementary/1471-2202-1114-S10.PDF ]

Additional file 11: Elaboration of PDGFR $\alpha$ on bipotent neuronal/ oligodendrocyte precursors (N/OPs) independent of PDGF-AA application following propagation in vitro. N/OPs at $2 \mathrm{~h}(\mathrm{~A}-\mathrm{B})$ in vitro express the bHLH transcription factors, Olig2 and Mash1 (A), in addition to nestin (B). Immunofluorescence microscopic analysis reveals that PDGFR $\alpha$ is not initially expressed by this cellular species in our clonal culture paradigm. However, PDGFR $\alpha$ expression is unequivocally present at $24 \mathrm{~h}$ (C-D, arrowheads), demonstrating that N/OPs begin to acquire PDGFR $\alpha$ expression and responsiveness to PDGF-AA, which is required for proliferation and migration of OL progenitors following specification. Click here for file

[http://www.biomedcentral.com/content/supplementary/1471-2202-1114-S11.PDF ]
Additional file 12: Gene expression profiles of ncRNAs during oligodendrocyte differentiation. Correlation of expression profiles of ncRNAs with protein-coding gene markers during

oligodendrogliogenesis. Genes with well-characterized roles in oligodendrogenesis were used to identify ncRNAs with correlated expression profiles (Pearson's coefficient $>0.9$ ). This included Olig1 (A; purple) and Stm2 (B; red) that are differentially expressed in OLPs or Mobp ( $\mathbf{C}$; blue) or Melk ( $\mathbf{D}$; pink) that are differentially expressed during terminal differentiation to MYOs. NcRNA accession IDs are available in Additional file 13.

Click here for file

[http://www.biomedcentral.com/content/supplementary/1471-2202-1114-S12.PDF ]

Additional file 13: Noncoding RNAs that exhibit concordant expression profiles with marker genes with well-characterized roles in neuronal and oligodendrocyte differentiation. Genes with wellcharacterized roles in oligodendrogliogenesis were used to identify ncRNAs with correlated expression profiles (Pearson's coefficient $>0.9$ ). These genes include Olig1, Stmn2, Mobp, Melk, MOG, Mash1 and Nkx2-2. Illustration of selected expression profiles is shown in Additional file 13. Click here for file

[http://www.biomedcentral.com/content/supplementary/1471-2202-1114-S13.XLS]

Additional file 14: The Sox8 gene and associated Sox8OT ncRNA share a dynamically modified chromatin domain. The genome browser view shows the bidirectional organization of the Sox8 gene (blue) and the Sox8OT ncRNA (red). A shared promoter region (shaded box) exhibits dynamic chromatin remodeling in embryonic stem cells ( $A$; ES), embryonic fibroblasts (B; MEF) and neural progenitors (C; NP) [61]. The combination of active H3K4me3 (green histogram) and repressive H3K27me3 (red histogram) modified chromatin, observed in ES and MEF cells, is termed a bivalent domain and is indicative of a gene in a 'poised' state for activation. This is reflected in the low prevalence of H3K36me3 modified chromatin (blue histogram) that is normally associated with RNA Polymerase elongation. In NPs the bivalent domain has been resolved to an active H3K4me3 domain and the presence of H3K36me3 modified domains implies that both the Sox8 and Sox8OT transcripts are concordantly upregulated. Tpm; tags per million. Click here for file

[http://www.biomedcentral.com/content/supplementary/1471-2202-1114-S14.PDF ]

Additional file 15: The HDAC inhibitor TSA prevents the acquisition of secondary morphological features of differentiating PMOs with concurrent alteration in the expression profiles of ncRNAs under instructive conditions (CNTF treatment) and stochastic (CNTF naïve) for OL lineage maturation. (A-D) Immunofluorescence micrographs demonstrating the profiles of $\mathrm{OL}$ lineage species in the absence $(A, B)$ or presence $(C, D)$ of TSA at T1 $(24 h, A, C)$ and T2 $(48 h, B, D)$ in the presence of CNTF with concurrent PDGF-AA factor withdrawal. (E, F) The effects of TSA application on comparative expression profiles of ncRNAs as assessed at T1 (E) and at T2 (F) in relation to the timing of TSA exposure in the experimental conditions. (G-K) Immunofluorescence micrographs demonstrating the profiles of $\mathrm{OL}$ lineage species in the absence $(G, H)$ or presence $(J, K)$ of TSA at T1 $(24 h, G, J)$ and T2 $(48 \mathrm{~h}, \mathrm{H}$, $K)$ in the presence PDGF-AA factor withdrawal only. $(L, M)$ The effects of TSA application on comparative expression profiles of ncRNAs assessed at $\mathrm{T1}(\mathrm{L})$ and at $\mathrm{T} 2(\mathrm{M})$ in relation to the timing of TSA exposure in the experimental conditions.

Click here for file

[http://www.biomedcentral.com/content/supplementary/1471-2202-1114-S15.PDF ]

Additional file 16: List of ncRNA primers used in the validation of microarray results by QRT-PCR.

Click here for file

[http://www.biomedcentral.com/content/supplementary/1471-2202-1114-S16.XLS ] 


\section{Acknowledgements}

TRM was supported by an Australian Postgraduate Award. MED was funded by a Foundation for Research, Science, and Technology, New Zealand Fellowship. JSM is supported by an Australian Research Council Federation Fellowship (FF0561986), as well as by the University of Queensland and the Queensland State Government. MFM is supported by grants from the National Institutes of Health (NS38902, MH66290, HD01799), as well as by the F.M. Kirby, the Rosanne H. Silbermann, the Alpern Family, the Mildred and Bernard H. Kayden and the Roslyn and Leslie Goldstein Foundations.

\section{Author details}

'Institute for Molecular Bioscience, University of Queensland, 306 Carmody Road, Brisbane, QLD 4072, Australia. ${ }^{2}$ Institute for Brain Disorders and Neural Regeneration, Albert Einstein College of Medicine, Bronx, New York, NY 10461, USA. ${ }^{3}$ Department of Neurology, Albert Einstein College of Medicine, Bronx, New York, NY 10461, USA. ${ }^{4}$ Department of Psychiatry and Behavioral Sciences, Albert Einstein College of Medicine, Bronx, New York, NY 10461, USA. ${ }^{5}$ Einstein Cancer Center, Albert Einstein College of Medicine, Bronx, New York, NY 10461, USA. 'Rose F Kennedy Center for Research on Intellectual and Developmental Disabilities, Albert Einstein College of Medicine, Bronx, New York, NY 10461, USA.

\section{Authors' contributions}

TRM, MED and IAQ analyzed the microarray data and drafted the manuscript. SG participated in the study design, carried out cell culture studies, immunohistochemical protocols and helped to draft the manuscript. GL performed microarray studies and additional molecular genetic assays. JSM and MFM conceived the study, participated in its design and coordination, and helped to draft the manuscript.

Received: 27 June 2009

Accepted: 5 February 2010 Published: 5 February 2010

\section{References}

1. Carninci P, Kasukawa T, Katayama S, Gough J, Frith MC, Maeda N, Oyama R, Ravasi T, Lenhard B, Wells $C$, et al: The transcriptional landscape of the mammalian genome. Science 2005, 309:1559-1563.

2. Mattick JS, Makunin IV: Non-coding RNA. Hum Mol Genet 2006, 15:R17-29.

3. Kapranov P, Willingham AT, Gingeras TR: Genome-wide transcription and the implications for genomic organization. Nat Rev Genet 2007, 8:413-423.

4. Amaral PP, Mattick JS: Noncoding RNA in development. Mamm Genome 2008, 19:454-492.

5. Mercer TR, Dinger ME, Mattick JS: Long non-coding RNAs: insights into functions. Nat Rev Genet 2009, 10:155-159.

6. Mercer TR, Dinger ME, Sunkin SM, Mehler MF, Mattick JS: Specific expression of long noncoding RNAs in the mouse brain. Proc Natl Acad Sci USA 2008, 105:716-721.

7. Dinger ME, Amaral PP, Mercer TR, Pang KC, Bruce SJ, Gardiner BB, AskarianAmiri ME, Ru K, Soldà G, Simons C, et al: Long noncoding RNAs in mouse embryonic stem cell pluripotency and differentiation. Genome Res 2008, 18:1433-1445.

8. Pang KC, Dinger ME, Mercer TR, Malquori L, Grimmond SM, Chen W, Mattick JS: Genome-wide identification of long noncoding RNAs in CD8+ T cells. J Immunol 2009, 182:7738-7748.

9. Mehler MF, Mattick JS: Noncoding RNAs and RNA editing in brain development, functional diversification, and neurological disease. Physiol Rev 2007, 87:799-823.

10. Mehler MF, Mattick JS: Non-coding RNAs in the nervous system. J Physiol 2006, 575:333-341

11. Prasanth KV, Spector DL: Eukaryotic regulatory RNAs: an answer to the 'genome complexity' conundrum. Genes Dev 2007, 21:11-42.

12. Mattick JS, Amaral PP, Dinger ME, Mercer TR, Mehler MF: RNA regulation of epigenetic processes. Bioessays 2009, 31:51-59.

13. Mattick JS: The genetic signatures of noncoding RNAs. PLoS Genet 2009, 5:e1000459.

14. Schwartz JC, Younger ST, Nguyen NB, Hardy DB, Monia BP, Corey DR, Janowski BA: Antisense transcripts are targets for activating small RNAs. Nat Struct Mol Biol 2008, 15:842-848.

15. Morris KV, Santoso S, Turner AM, Pastori C, Hawkins PG: Bidirectional transcription directs both transcriptional gene activation and suppression in human cells. PLOS Genet 2008, 4:e1000258.
16. Chojnacki A, Weiss S: Isolation of a novel platelet-derived growth factorresponsive precursor from the embryonic ventral forebrain. J Neurosci 2004, 24:10888-10899.

17. He W, Ingraham C, Rising L, Goderie S, Temple S: Multipotent stem cells from the mouse basal forebrain contribute GABAergic neurons and oligodendrocytes to the cerebral cortex during embryogenesis. J Neurosci 2001, 21:8854-8862.

18. Corbin JG, Nery S, Fishell G: Telencephalic cells take a tangent: non-radial migration in the mammalian forebrain. Nat Neurosci 2001 4(Suppl):1177-1182.

19. Parnavelas JG, Alifragis $P$, Nadarajah $B$ : The origin and migration of cortical neurons. Prog Brain Res 2002, 136:73-80

20. Yung SY, Gokhan S, Jurcsak J, Molero AE, Abrajano JJ, Mehler MF: Differential modulation of BMP signaling promotes the elaboration of cerebral cortical GABAergic neurons or oligodendrocytes from a common sonic hedgehog-responsive ventral forebrain progenitor species. Proc Natl Acad Sci USA 2002, 99:16273-16278.

21. Anderson SA, Marin O, Horn C, Jennings K, Rubenstein JL: Distinct cortical migrations from the medial and lateral ganglionic eminences. Development 2001, 128:353-363.

22. Cunliffe VT, Casaccia-Bonnefil P: Histone deacetylase 1 is essential for oligodendrocyte specification in the zebrafish CNS. Mech Dev 2006, 123:24-30.

23. He Y, Dupree J, Wang J, Sandoval J, Li J, Liu H, Shi Y, Nave KA, CasacciaBonnefil P: The transcription factor Yin Yang 1 is essential for oligodendrocyte progenitor differentiation. Neuron 2007, 55:217-230

24. He Y, Sandoval J, Casaccia-Bonnefil P: Events at the transition between cell cycle exit and oligodendrocyte progenitor differentiation: the role of HDAC and YY1. Neuron Glia Biol 2007, 3:221-231.

25. Marin-Husstege M, Muggironi M, Liu A, Casaccia-Bonnefil P: Histone deacetylase activity is necessary for oligodendrocyte lineage progression. J Neurosci 2002, 22:10333-10345.

26. Shen S, Casaccia-Bonnefil P: Post-translational modifications of nucleosomal histones in oligodendrocyte lineage cells in development and disease. J Mol Neurosci 2008, 35:13-22.

27. Kapranov P, Cheng J, Dike S, Nix DA, Duttagupta R, Willingham AT, Stadler PF, Hertel J, Hackermuller J, Hofacker IL, et al: RNA maps reveal new RNA classes and a possible function for pervasive transcription. Science 2007, 316:1484-1488,

28. Mattick JS: A new paradigm for developmental biology. J Exp Biol 2007, 210:1526-1547.

29. Rinn JL, Kertesz M, Wang JK, Squazzo SL, Xu X, Brugmann SA, Goodnough LH, Helms JA, Farnham PJ, Segal E, et al: Functional demarcation of active and silent chromatin domains in human HOX loci by noncoding RNAs. Cell 2007, 129:1311-1323.

30. Yu W, Gius D, Onyango P, Muldoon-Jacobs K, Karp J, Feinberg AP, Cui H: Epigenetic silencing of tumour suppressor gene p15 by its antisense RNA. Nature 2008, 451:202-206.

31. Feng J, Bi C, Clark BS, Mady R, Shah P, Kohtz JD: The Evf-2 noncoding RNA is transcribed from the Dlx $-5 / 6$ ultraconserved region and functions as a Dlx-2 transcriptional coactivator. Genes Dev 2006, 20:1470-1484.

32. Meyer NP, Roelink $\mathrm{H}$ : The amino-terminal region of Gli3 antagonizes the Shh response and acts in dorsoventral fate specification in the developing spinal cord. Dev Biol 2003, 257:343-355.

33. Hashimoto-Torii K, Motoyama J, Hui CC, Kuroiwa A, Nakafuku M, Shimamura K: Differential activities of Sonic hedgehog mediated by Gli transcription factors define distinct neuronal subtypes in the dorsal thalamus. Mech Dev 2003, 120:1097-1111.

34. Washietl S, Hofacker IL, Lukasser M, Huttenhofer A, Stadler PF: Mapping of conserved RNA secondary structures predicts thousands of functional noncoding RNAs in the human genome. Nat Biotechnol 2005, 23:1383-1390.

35. Ye K: H/ACA guide RNAs, proteins and complexes. Curr Opin Struct Biol 2007, 17:287-292.

36. Perron MP, Provost P: Protein interactions and complexes in human microRNA biogenesis and function. Front Biosci 2008, 13:2537-2547.

37. Fedor MJ, Williamson JR: The catalytic diversity of RNAs. Nat Rev Mol Cell Biol 2005, 6:399-412.

38. Battiste J, Helms AW, Kim EJ, Savage TK, Lagace DC, Mandyam CD, Eisch AJ, Miyoshi G, Johnson JE: Ascl1 defines sequentially generated lineage- 
restricted neuronal and oligodendrocyte precursor cells in the spinal cord. Development 2007, 134:285-293.

39. Parras CM, Hunt C, Sugimori M, Nakafuku M, Rowitch D, Guillemot F: The proneural gene Mash1 specifies an early population of telencephalic oligodendrocytes. J Neurosci 2007, 27:4233-4242.

40. Jessberger S, Toni N, Clemenson GD Jr, Ray J, Gage FH: Directed differentiation of hippocampal stem/progenitor cells in the adult brain. Nat Neurosci 2008, 11:888-893.

41. Sone M, Hayashi T, Tarui H, Agata K, Takeichi M, Nakagawa S: The mRNAlike noncoding RNA Gomafu constitutes a novel nuclear domain in a subset of neurons. J Cell Sci 2007, 120:2498-2506.

42. Hutchinson JN, Ensminger AW, Clemson CM, Lynch CR, Lawrence JB, Chess A: A screen for nuclear transcripts identifies two linked noncoding RNAs associated with SC35 splicing domains. BMC Genomics 2007, 8:39.

43. Popovici C, Fallet M, Marguet D, Birnbaum D, Roubin R: Intracellular trafficking of LET-756, a fibroblast growth factor of C. elegans, is controlled by a balance of export and nuclear signals. Exp Cell Res 2006, 312:1484-1495.

44. Ulfig N, Briese V: Immunolabelling of spliceosomes in sections and cultured astrocytes of human fetal brain tissue. Brain Dev 1999, 21:51-58.

45. Sunwoo H, Dinger ME, Wilusz JE, Amaral PP, Mattick JS, Spector DL: MEN epsilon/beta nuclear-retained non-coding RNAs are up-regulated upon muscle differentiation and are essential components of paraspeckles. Genome Res 2009, 19:347-359.

46. Clemson CM, Hutchinson JN, Sara SA, Ensminger AW, Fox AH, Chess A, Lawrence JB: An architectural role for a nuclear noncoding RNA: NEAT1 RNA is essential for the structure of paraspeckles. Mol Cell 2009, 33:717-726.

47. Sasaki YT, Ideue T, Sano M, Mituyama T, Hirose T: MENepsilon/beta noncoding RNAs are essential for structural integrity of nuclear paraspeckles. Proc Natl Acad Sci USA 2009, 106:2525-2530.

48. Sempere LF, Freemantle S, Pitha-Rowe I, Moss E, Dmitrovsky E, Ambros V: Expression profiling of mammalian microRNAs uncovers a subset of brain-expressed microRNAs with possible roles in murine and human neuronal differentiation. Genome Biol 2004, 5:R13.

49. Wulczyn FG, Smirnova L, Rybak A, Brandt C, Kwidzinski E, Ninnemann O, Strehle M, Seiler A, Schumacher S, Nitsch R: Post-transcriptional regulation of the let-7 microRNA during neural cell specification. Faseb J 2007, 21:415-426.

50. Lagos-Quintana M, Rauhut R, Yalcin A, Meyer J, Lendeckel W, Tuschl T: Identification of tissue-specific microRNAs from mouse. Curr Biol 2002 12:735-739.

51. Cao X, Pfaff SL, Gage FH: A functional study of miR-124 in the developing neural tube. Genes Dev 2007, 21:531-536.

52. Visvanathan J, Lee S, Lee B, Lee JW, Lee SK: The microRNA miR-124 antagonizes the anti-neural REST/SCP1 pathway during embryonic CNS development. Genes Dev 2007, 21:744-749.

53. Makeyev EV, Zhang J, Carrasco MA, Maniatis T: The microRNA miR-124 promotes neuronal differentiation by triggering brain-specific alternative pre-mRNA splicing. Mol Cell 2007, 27:435-448.

54. Guttman M, Amit I, Garber M, French C, Lin MF, Feldser D, Huarte M, Zuk O, Carey BW, Cassady JP, et al: Chromatin signature reveals over a thousand highly conserved large non-coding RNAs in mammals. Nature 2009, 458:223-227.

55. Pennacchio LA, Ahituv N, Moses AM, Prabhakar S, Nobrega MA, Shoukry M, Minovitsky S, Dubchak I, Holt A, Lewis KD, et al: In vivo enhancer analysis of human conserved non-coding sequences. Nature 2006, 444:499-502.

56. Petryniak MA, Potter GB, Rowitch DH, Rubenstein JL: Dlx1 and DIx2 control neuronal versus oligodendroglial cell fate acquisition in the developing forebrain. Neuron 2007, 55:417-433.

57. Marin $\mathrm{O}$, Rubenstein $\mathrm{JL}$ : A long, remarkable journey: tangential migration in the telencephalon. Nat Rev Neurosci 2001, 2:780-790.

58. Marin O, Rubenstein JL: Cell migration in the forebrain. Annu Rev Neurosci 2003, 26:441-483.

59. Kellerer S, Schreiner S, Stolt CC, Scholz S, Bosl MR, Wegner M: Replacement of the Sox 10 transcription factor by Sox8 reveals incomplete functional equivalence. Development 2006, 133:2875-2886.

60. Stolt CC, Schmitt S, Lommes P, Sock E, Wegner M: Impact of transcription factor Sox8 on oligodendrocyte specification in the mouse embryonic spinal cord. Dev Biol 2005, 281:309-317.
61. Mikkelsen TS, Ku M, Jaffe DB, Issac B, Lieberman E, Giannoukos G, Alvarez P, Brockman W, Kim TK, Koche RP, et al: Genome-wide maps of chromatin state in pluripotent and lineage-committed cells. Nature 2007, 448:553-560

62. Cahoy JD, Emery B, Kaushal A, Foo LC, Zamanian JL, Christopherson KS, Xing Y, Lubischer JL, Krieg PA, Krupenko SA, et al: A transcriptome database for astrocytes, neurons, and oligodendrocytes: a new resource for understanding brain development and function. J Neurosci 2008, 28:264-278.

63. Casaccia-Bonnefil P, Tikoo R, Kiyokawa H, Friedrich V Jr, Chao MV, Koff A: Oligodendrocyte precursor differentiation is perturbed in the absence of the cyclin-dependent kinase inhibitor p27Kip1. Genes Dev 1997, 11:2335-2346.

64. Durand B, Raff M: A cell-intrinsic timer that operates during oligodendrocyte development. Bioessays 2000, 22:64-71.

65. Kondo T, Raff M: The Id4 HLH protein and the timing of oligodendrocyte differentiation. Embo J 2000, 19:1998-2007.

66. Nguyen L, Borgs L, Vandenbosch R, Mangin JM, Beukelaers P, Moonen G, Gallo V, Malgrange B, Belachew S: The Yin and Yang of cell cycle progression and differentiation in the oligodendroglial lineage. Ment Retard Dev Disabil Res Rev 2006, 12:85-96.

67. Boggs JM: Myelin basic protein: a multifunctional protein. Cell Mol Life Sci 2006, 63:1945-1961.

68. Kee HJ, Ahn KY, Choi KC, Won Song J, Heo T, Jung S, Kim JK, Bae CS, Kim KK: Expression of brain-specific angiogenesis inhibitor 3 (BAl3) in normal brain and implications for BAl3 in ischemia-induced brain angiogenesis and malignant glioma. FEBS Lett 2004, 569:307-316.

69. Engels H, Brockschmidt A, Hoischen A, Landwehr C, Bosse K, Walldorf C, Toedt G, Radlwimmer B, Propping P, Lichter P, et al: DNA microarray analysis identifies candidate regions and genes in unexplained mental retardation. Neurology 2007, 68:743-750.

70. DeRosse P, Lencz T, Burdick KE, Siris SG, Kane JM, Malhotra AK: The genetics of symptom-based phenotypes: toward a molecular classification of schizophrenia. Schizophr Bull 2008, 34:1047-1053.

71. Gokhan S, Marin-Husstege M, Yung SY, Fontanez D, Casaccia-Bonnefil P, Mehler MF: Combinatorial profiles of oligodendrocyte-selective classes of transcriptional regulators differentially modulate myelin basic protein gene expression. J Neurosci 2005, 25:8311-8321.

72. Marmur R, Kessler JA, Zhu G, Gokhan S, Mehler MF: Differentiation of oligodendroglial progenitors derived from cortical multipotent cells requires extrinsic signals including activation of gp130/LIFbeta receptors. J Neurosci 1998, 18:9800-9811.

73. Zezula J, Casaccia-Bonnefil P, Ezhevsky SA, Osterhout DJ, Levine JM, Dowdy SF, Chao MV, Koff A: p21cip1 is required for the differentiation of oligodendrocytes independently of cell cycle withdrawal. EMBO Rep 2001, 2:27-34.

74. Amiguet P, Gardinier MV, Zanetta JP, Matthieu JM: Purification and partial structural and functional characterization of mouse myelin/ oligodendrocyte glycoprotein. J Neurochem 1992, 58:1676-1682.

75. Cordes S, Frank CA, Garriga G: The C. elegans MELK ortholog PIG-1 regulates cell size asymmetry and daughter cell fate in asymmetric neuroblast divisions. Development 2006, 133:2747-2756.

76. Moustakas A, Heldin CH: Ecsit-ement on the crossroads of Toll and BMP signal transduction. Genes Dev 2003, 17:2855-2859.

77. Xiao C, Shim JH, Kluppel M, Zhang SS, Dong C, Flavell RA, Fu XY, Wrana JL, Hogan BL, Ghosh S: Ecsit is required for Bmp signaling and mesoderm formation during mouse embryogenesis. Genes Dev 2003, 17:2933-2949.

78. Liu A, Han YR, Li J, Sun D, Ouyang M, Plummer MR, Casaccia-Bonnefil P: The glial or neuronal fate choice of oligodendrocyte progenitors is modulated by their ability to acquire an epigenetic memory. J Neurosci 2007, 27:7339-7343.

79. Shen S, Li J, Casaccia-Bonnefil P: Histone modifications affect timing of oligodendrocyte progenitor differentiation in the developing rat brain. $J$ Cell Biol 2005, 169:577-589.

80. Shen S, Sandoval J, Swiss VA, Li J, Dupree J, Franklin RJ, Casaccia-Bonnefil P: Age-dependent epigenetic control of differentiation inhibitors is critical for remyelination efficiency. Nat Neurosci 2008, 9:1024-1034.

81. Shen S, Liu A, Li J, Wolubah C, Casaccia-Bonnefil P: Epigenetic memory loss in aging oligodendrocytes in the corpus callosum. Neurobiol Aging 2008, 29:452-463. 
82. Birling MC, Tait S, Hardy RJ, Brophy PJ: A novel rat tetraspan protein in cells of the oligodendrocyte lineage. J Neurochem 1999, 73:2600-2608.

83. Tiwari-Woodruff SK, Buznikov AG, Vu TQ, Micevych PE, Chen K, Kornblum HI Bronstein JM: OSP/Claudin-11 forms a complex with a novel member of the tetraspanin super family and beta 1 integrin and regulates proliferation and migration of oligodendrocytes. J Cell Biol 2001 153:295-305.

84. Balasubramaniyan V, Boddeke E, Bakels R, Kust B, Kooistra S, Veneman A, Copray S: Effects of histone deacetylation inhibition on neuronal differentiation of embryonic mouse neural stem cells. Neuroscience 2006, 143:939-951.

85. McLaughlin D, Vidaki M, Renieri E, Karagogeos D: Expression pattern of the maternally imprinted gene Gtl2 in the forebrain during embryonic development and adulthood. Gene Expr Patterns 2006, 6:394-399.

86. Dugas JC, Tai YC, Speed TP, Ngai J, Barres BA: Functional genomic analysis of oligodendrocyte differentiation. J Neurosci 2006, 26:10967-10983.

87. Tochitani S, Hayashizaki Y: Nkx2.2 antisense RNA overexpression enhanced oligodendrocytic differentiation. Biochem Biophys Res Commun 2008, 372:691-696.

88. Ravasi T, Suzuki H, Pang KC, Katayama S, Furuno M, Okunishi R, Fukuda S, Ru K, Frith MC, Gongora MM, et al: Experimental validation of the regulated expression of large numbers of non-coding RNAs from the mouse genome. Genome Res 2006, 16:11-19.

89. Szymanski M, Barciszewska MZ, Erdmann VA, Barciszewski J: A new frontier for molecular medicine: noncoding RNAs. Biochim Biophys Acta 2005, 1756:65-75.

90. Zhu G, Mehler MF, Mabie PC, Kessler JA: Developmental changes in progenitor cell responsiveness to cytokines. J Neurosci Res 1999 56:131-145.

91. Mehler MF: Mechanisms regulating lineage diversity during mammalian cerebral cortical neurogenesis and gliogenesis. Results Probl Cell Differ 2002, 39:27-52

92. Mehler MF: Regional forebrain patterning and neural subtype specification: implications for cerebral cortical functional connectivity and the pathogenesis of neurodegenerative diseases. Results Probl Cell Differ 2002, 39:157-178.

93. Marmur R, Mabie PC, Gokhan S, Song Q, Kessler JA, Mehler MF: Isolation and developmental characterization of cerebral cortical multipotent progenitors. Dev Biol 1998, 204:577-591.

94. Griffiths-Jones S, Grocock RJ, van Dongen S, Bateman A, Enright AJ: miRBase: microRNA sequences, targets and gene nomenclature. Nucleic Acids Res 2006, 34:D140-144.

95. Smyth GK, Speed T: Normalization of cDNA microarray data. Methods 2003, 31:265-273.

96. Smyth GK: Linear models and empirical bayes methods for assessing differential expression in microarray experiments. Stat Appl Genet Mol Biol 2004, 3, Article3.

97. Pfaffl MW, Horgan GW, Dempfle L: Relative expression software tool (REST) for group-wise comparison and statistical analysis of relative expression results in real-time PCR. Nucleic Acids Res 2002, 30:e36.

98. Kent WJ: BLAT-the BLAST-like alignment tool. Genome Res 2002, 12:656-664.

99. Do CB, Woods DA, Batzoglou S: CONTRAfold: RNA secondary structure prediction without physics-based models. Bioinformatics 2006, 22:e90-98.

100. Al-Shahrour F, Carbonell J, Minguez P, Goetz S, Conesa A, Tarraga J, Medina I, Alloza E, Montaner D, Dopazo J: Babelomics: advanced functional profiling of transcriptomics, proteomics and genomics experiments. Nucleic Acids Res 2008, 36:W341-346.

101. Washietl S, Hofacker IL: Identifying structural noncoding RNAs using RNAz. Curr Protoc Bioinformatics 2007, Chapter 12(Unit 12.7)

102. Dinger ME, Pang KC, Mercer TR, Crowe ML, Grimmond SM, Mattick JS: NRED: a database of long noncoding RNA expression. Nucleic Acids Res 2009, 37:D122-126.

doi:10.1186/1471-2202-11-14

Cite this article as: Mercer et al:: Long noncoding RNAs in neuronal-glial fate specification and oligodendrocyte lineage maturation. BMC Neuroscience 2010 11:14

\section{Submit your next manuscript to BioMed Central and take full advantage of:}

- Convenient online submission

- Thorough peer review

- No space constraints or color figure charges

- Immediate publication on acceptance

- Inclusion in PubMed, CAS, Scopus and Google Scholar

- Research which is freely available for redistribution

Submit your manuscript at www.biomedcentral.com/submit 